\title{
Problems and Prospects of Millennium Development Goals in Ghana
}

\author{
OLASUP0, 0. | PLAATJIE, S.R.
}

\section{Abstract}

G hana, like other developing nations, was not left behind in embracing the eight time-bound Millennium Development Goals (MDGs) in September 2000. The millennium development goals aimed towards peace and good standards of living have been faced with series of problems in its attainment in Ghana. These problems have undermined the extent to which Ghana could achieve the MDGs. The study adopting qualitative research method shows that Ghana is faced with difficulty in achieving these eight millennium development goals in certain portions of the nation most especially in the rural communities due to lack of infrastructure. The study therefore recommends that Ghana should focus more on improving the standard of living of the rural dwellers by increasing the public services in the area. The need for Ghana to focus more on solving these problems is strategic for a better result in this new era of Sustainable Development Goals.

Keywords: Housing, Migration, Urbanization, Population Growth, Obstacles, Informal Settlements, Ekurhuleni Municipality, South Africa. 


\section{Introduction}

The Millennium Development Goals (programme) was declared and adopted by the world leaders in 2000 during the United Nations Summit. It was a proclamation for global attainment of unity, peace and good standard of living for the citizens. The Millennium Development goals were targeted towards tackling some development crises such as poverty, unemployment, and some other world development urgency at the most critical time of the millennium in year 2000.

Ghana, among other 188 member States present at the United Nations General Assembly, approved 8 Millennium Development Goals. These goals cut across every area of development that needs critical attention. They are as follows in ascending order: eradication of acute poverty and hunger, provision of general basic education, promotion of gender parity and women's emancipation, reduction of infant death, enhancement of maternity health, fighting HIV/AIDS, malaria and other ailments, safeguarding the environment and building a world alliance for development.

\section{Figure 1: Ghana among other $188 \mathrm{UN}$ member countries adopting $8 M D G S$}

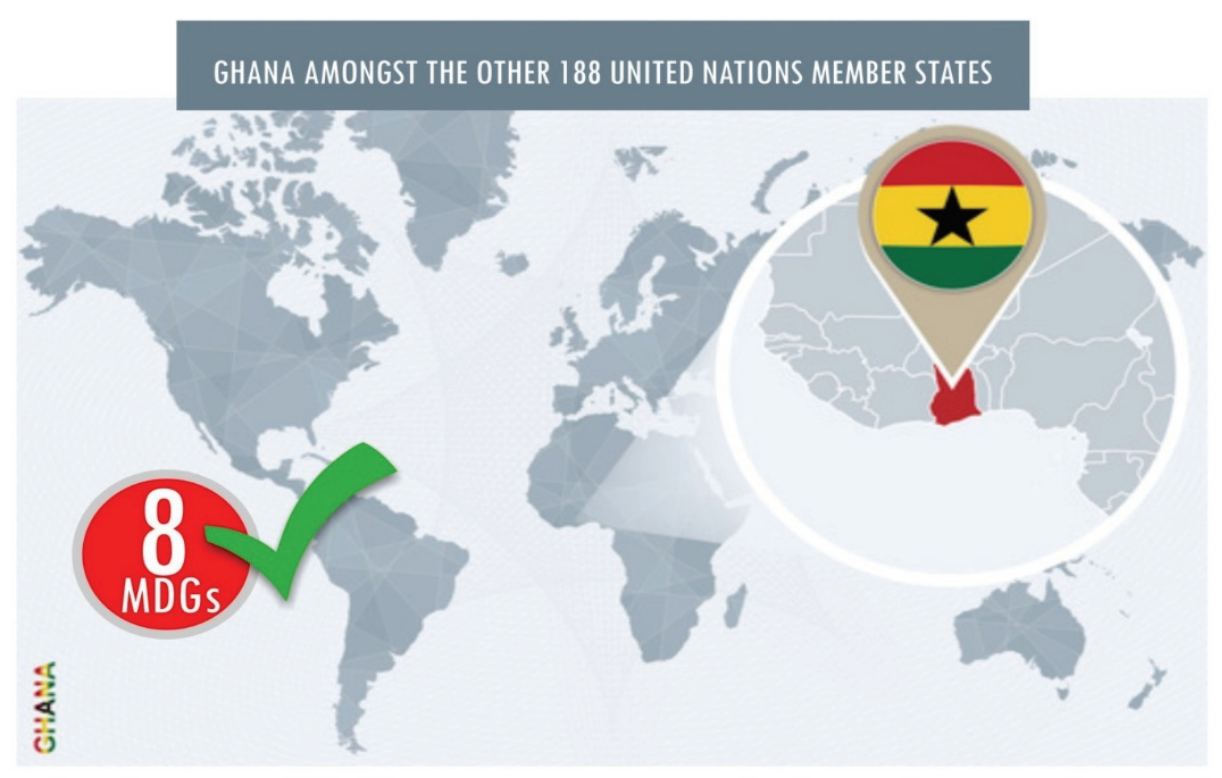


Ghana was devoted to implementing these millennium development objectives by incorporating them into the national policy. Ghana started recording advancement on the attainment of the Millennium Development Goals since 2002 with two-yearly special MDGs report.

\section{Ghana's Development Background}

Ghana is a tropical nation in West Africa sub-region with the population estimated to 26.6 million in year 2013 (GLSS). Ghana has 10 regions and 216 districts with democratic system of government. The country is predominantly Christians with 74 percent while the Islamic religion faithful represents 18.5 and traditional with other religions representing 7.5 percent.

Agriculture was the major economy in Ghana until 2006 when other economic sectors such as industry, services and mining began to improve. The country is rich in timber, gold, diamond, cocoa, manganese and other resources which constitute the foreign exchange for Ghana. The recent speedy economic growth in Ghana has made it one of the fast developing nations in Africa.

Figure 2: Ghana's Background and West Africa Map

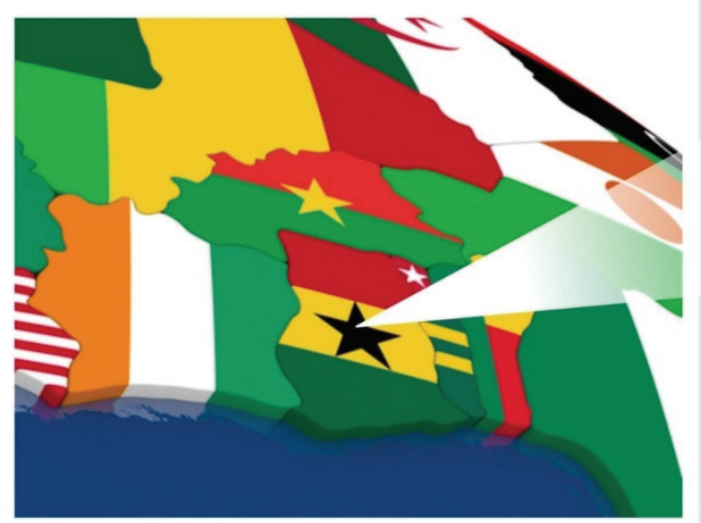

10 REGIONS

26.6 MILLION PEOPLE

DEMOCRATIC NATION

AGRO BASED ECONOMY UNTIL 2006

NOW: SERVICES, MINING \& INDUSTRY 


\section{Statement of the Problem}

Although Ghana has the United Nations' deadline in some areas of Millennium Development Goals by halving them ahead of the deadline, but the nation still needs to exert more efforts to fully attain all these objectives. The need to tackle the challenges that are facing the outright success of the development goals is therefore urgent and important towards the growth and advancement of Ghana. These problems of millennium development goals have the capacity to undermine the efforts of Ghana if not improved upon. These challenges are common to Volta region, the three Northern regions and rural areas, especially on reduction of extreme poverty (Ghana Statistics Service, GLSS 6 2014).

\section{Theoretical Framework}

There are numbers of development theories, but this study is better explained by the modernization theory. Several countries all over the world at the end of colonial rule fell in the categories of developing and underdeveloped. The quest for development by these newly independent nations made them to embark on developmental activities. Most of these newly independent countries began to seek development from within rather than continued dependence on their former colonial leaders. This led to the development of indigenous industries in some countries to strengthen their export power while others improved on their production capacity to meet the demand of their citizens and discourage importation. Industrialization therefore became a measure of meeting up with the Western standard of development set by them long ago.

Modernization is one of the foremost theories in social sciences. It was derived from biological sciences of the study of growth and development. This growth and development was applied to the societies, political organizations and the economic sectors which were considered to be a growing species. Europe and American development strategy became a standard for the whole world to follow.

There are different views to the concept of modernization by various scholars of old. Some of these scholars attempted the definition of modernization as a means of social transformation (Michael \& John 2001). Other scholars view modernization beyond changes alone but as well as a reaction to change. Modernization theory was criticized for not taking into consideration the uniqueness of each society and how western modernization may not be applicable to non-European and non-Western states. 
Despite the limitations of these theories, scholars such as Aboderin (2004) and Arts et al., (1999) still find it relevant. They argued that modernization theory describe the economic and social dynamics in many countries until now.

Therefore, the need for a concerted effort for global development most especially to assist the under-developed and the developing nations in most critical areas of development through funding, technology and new markets has made the world leaders under the United Nations to adopt millennium development goals in year 2000 as the major standard for the world development. The major thrust of millennium development goals being an extension of modernization process is to raise the standard of living of the poor countries most especially in Africa.

\section{Problems of Millennium Development Goals in Ghana}

Despite the success of Ghana in halving most of the millennium development goals ahead of the deadline which was 2015, the country is still faced with series of problems towards actualizing these goals in some parts of the country most especially in the rural areas (Ghana Statistics Service 2014). Irrespective of these glaring results of the millennium development goals, the following problems have undermined Ghana's ability to perform much better. The uniqueness of these problems to each of the millennium development goals is discussed one after the other.

\section{Eradication of Extreme Hunger and Poverty}

The determination of the government of Ghana to meet up with this millennium goal on the eradication of extreme hunger and poverty was a remarkable one as Ghana assumed the number one nation in West Africa to reach the target of reducing extreme poverty by 2015 (MDG Report 2010). The number of people categorized under extreme poverty both in the city and remote areas in seven provinces were halved in 2006. The chance of improvement in the three Northern regions that are below the target is high due to the review of poverty in the regions. Despite this landslide result, Ghana is still faced with extreme difficulty of reducing poverty in the three regions of the North and Upper west Region of the country. It is noted that the numbers of people with inferior and nonrewarding job is still on the increase. The problems that undermine the total success of this goal of eradication of extreme hunger and poverty are therefore discussed as follows: 
- The inability of Ghana to fully embrace mechanized farming, irrigation system and other contemporary farming techniques has affected the level of food crop production.

- Poor Infrastructure: The poor areas of Ghana are characterized by poor public services such as good roads, electricity and pipe borne water. The bad situation of road in rural areas has affected the transportation of agricultural products from rural areas to urban areas for economic purpose. This has led to loss of farm products that can reduce the level of poverty in Ghana.

- Many food crop farmers run into loss as a result of non-regularization of price which usually affects farmer's income.

\section{Achieve Universal Primary Education}

The commitment of Ghana to universal basic education both in policy and actions is reflected in the huge success of the programme in most parts of the country through the increase in primary school enrolment as a result of government intervention in free feeding, uniform and capitation grant (EMIS, Ministry of Education, 2014). The government of Ghana surpasses both the gross student registration and finishing goal. The student registrations exceeded the target with 107 percent both in 2013 and 2014. The degrees of completion in basic schools also overshot the expectation by 12.4 percent. This goal was accomplished with huge success but irrespective of this success, the following problems still persist.

- There are more indigent students from the rural areas whose parents and guardians are not economically buoyant enough to sponsor them in higher institution. The cost of education has made education inaccessible to the poor that mostly comes from rural areas.

- Most teachers prefer urban cities to rural areas. This has affected the remote schools in Ghana from having adequate and qualified teaching personnel which is more reflected in student quality from rural areas.

- The dedication of teachers is affected by the poor condition of service in education sector when compared to other sectors. This has effect on the quality of teaching and invariably affects the quality of the products in public schools. 
- Lack of adequate infrastructure: Shortage of teaching spaces and other teaching and learning materials have negative impact on teaching-learning process thereby the affecting quality of education in Ghana.

\section{Gender Equality and Women Empowerment Promotion}

Gender equality promotion and women empowerment in Ghana has not gained the required momentum as stipulated by the millennium development goals. Several efforts by policies such as launching of women in governance fund, collation of women data in position of authority for the assessment of women contribution in decision making, women capacity building and more have not yielded up to the expected result (Ghana Living Standard Survey 3, 4, $5 \& 6$ ). Despite the above claim, there is significant progress such as the achievement of female equality in nursery, basic, junior and senior secondary institutions and also at private higher education in Ghana. There is increase in the number of women representatives in cabinet from 8.3 percent in 2008 general vote to 10.9 percent in 2012.

Ghana's inability to achieve this goal is attributed to the following challenges facing sex parity promotion and women emancipation:

- Female children are faced with social cultural challenges such as early marriage which affects their right to education.

- Low level of female student registration in secondary school and matriculation into higher institutions have effect on women access to public job and also discourage their involvement in decision making at the place that matters.

- The culture and societal norms excluded women from certain professions and practices which are believed only meant for men. This affects the women equality and empowerment.

\section{Reduction of Child Mortality}

The health interventions such as immunization of children, neonatal and postnatal health care, child health policy, and child health strategy have more positive impact on reduction of child mortality in Ghana (Ghana Demographic Health Survey, 2014). The child mortality ratio in 1990 was 122 out of 1000 births while there is a significant improvement with the drop of child mortality to 82 out of 1000 births in 2012 but it is still below the 40 out of 
1000 target of the Millennium Development Goals. The above interventions and results reveal the success and the significant progress made by the Government of Ghana on this millennium development goal. The achievement in this regard would have been much more if the impediments that undermine this development goal were attended to.

- Inadequate fund for the continuity of intervention of child health programmes. The sustainability of these children support activities requires huge capital.

- Low level of education among women. This affects women in taking decisions that have to do with their children's health care. Such decision is solely left for the men in most families.

- Problem of accurate data on national child health. This did not help the government in making child policy.

- Insufficient human resources within the national health sector.

- Poor management of antenatal, neonatal and postnatal health care.

\section{Improved Maternal Health}

Despite several interventions to improve maternal health, several women still die yearly, although at a reduced rate on complications related to child birth such as bleeding, infections, hypertension, miscarriages and abortion. Ghana is yet to achieve the millennium development goal in this regard (World Health Organization, 2014). The maternal death is of increased rate. 451 mortality rates out of 100,000 births have been recorded for the past seven years against the target of 54 out of 100,000 births in 2015. The above indicators show the failure of this goal. The following problems have been identified as the undermining factors to the achievement of this millennium goal.

- There is lack of required attention on several government policies and approaches to meet up with the improvement of maternal health.

- Lack of adequate infrastructure and facilities such as ambulance service in most district hospitals.

- Lack of data: Unavailability of maternal health data is a major challenge that disallows the examination and plan for maternal health care in Ghana.

- Inadequate professional health workers, equipment and housing.

- The level of illiteracy is still very high among the rural women. Most women attempt self-delivery due to financial constraint.

- Distance of health facility and transportation problem. 


\section{HIV/AIDS, Malaria and Other Ailments Reduction}

The reduction in the spread of HIV/AIDS in Ghana is significant (Ministry of Health 20082012). This is as a result of government's aggressive fight against HIV/AIDS and the support received from World Bank, NGO's CSO's. The increase in HIV/AIDS in Ghana has reduced from 3.6 percent in 2007 to 1.3 percent in 2013 despite the prevalence of some regional inconsistence. The availability of anti-retroviral treatment is a plus to the reduction in HIV/AIDS in Ghana. Malaria is a major concern in Ghana being the main cause of mortality among children and pregnant women (National Malaria Control Programme Annual Report, 2009). Although efforts were made in combating malaria and HIV/AIDs such as distribution of Insecticide Treated Net (ITN) and anti-retroviral treatment with significant progress, this goal was not achieved.

The following problems therefore are the impediments to the attainment of this millennium development goal.

- Inadequate human resource and finance to combat HIV/AIDS and malaria.

- $\quad$ Problem of accountability and inefficient monitoring of HIV/AIDS and Malaria expenditure.

- Stigmatization and discrimination of people infected with HIV/AIDS is still highly prevalent.

- Bad hygienic lifestyle in urban areas.

- Poor waste management and bad sewage system.

- Lack of adequate distribution of Insecticide Treated Net (ITN) and poor usage especially among the poor.

\section{Ensure Environmental Sustainability}

Efforts made by Ghana to lessen the population without safe and clean water have not been duplicated in other areas of environmental sustainability. There is a drastic improvement in provision of clean water both in the urban and rural areas of Ghana (Ghana Demographic and Health Survey 1993-2008). There is still much to do to meet the target of reducing loss of resources, improvement on sanitation, to better the standard of living of people in slums and to reduce the alarming rate of deforestation. The rate of deforestation in Ghana is high while forestation by planting trees is very slow (Global Forest Assessment 2010). Irrespective of interventions by the government to ensure 
environmental sustainability, the following problems are still much glaring and need urgent attention if this millennium development goal will be accomplished.

- One of the major problems facing this millennium goal is weak policy enforcement most especially in the area of forestry and sanitation.

- Water availability is faced with the problem of increase demand in the face of speedy urbanization.

- Inadequate public services such as electricity and other sources of energy in case of water supply to population.

- Lack of private support to complement government effort in provision of clean water and environment.

- Poor waste management by industries and lack of hygiene among the populace.

\section{Enhancement of Global Relationship for Growth}

The democratic regime in Ghana which is characterized by transparency and accountability, respect of fundamental human rights, good practice of rule of law, good public service delivery, practice of separation of power, public security, women involvement in government and top public management and several other indicators of good governance and dividend of democracy has created a conducive environment for increased donors, capitalist economy that allows for individual and corporate ownership of business and investment and fast growing of multinational corporations. Many global investments in Africa even shift their base to Ghana due to the enabling environment for business and investment growth. The use of handset and internet facilities has drastically increased from 1.26 out of 100 subscribers in 2001 to 114.8 out of 100 in 2014 (Ghana MDGs 2015 Report). Internet subscription also has increased from 0.15\% population in 2000 to $18.9 \%$ in 2014. The above shows the huge success of this millennium development goal.

Regardless of exploit of Ghana to attract global partnership for development, the country is still faced with the following challenges.

- Inappropriate handling of aid due to lack of focus towards efficient result.

- Problem of corruption and misappropriation of public fund.

- The challenge of global economic meltdown. 


\section{Prospects of Millennium Development Goals in Ghana}

As a way forward, this study recommends that Ghana should focus more on improving the standard of living of the rural dwellers by increasing the public services in the area. The following are the recommended solutions to the challenges facing millennium development goals in Ghana.

- Ghana should increase allocations to the millennium development goals and seek grant and foreign aid to carry out interventions in every area of development goals that is yet to meet the standard of United Nations Development Programmes with proper monitoring of the spending.

- Improve on the production of cash and food crops through mechanized farming, irrigation and other contemporary means of agriculture.

- There is need for Ghana to enhance the social infrastructures such as road construction linking the rural areas where agricultural products are being cultivated, electricity, water, hospitals, etc.

- Provision of credit facilities to the citizens for small/medium scale business.

- Execution of education grants to reduce the high level of drop out by the indigent students and allowing more citizens to have access to quality education.

- In respect of universal basic education, government should intensify efforts on adequate infrastructure such as conducive classrooms, offices, instructional materials and improved condition of service for teachers.

- Government should provide incentives and inconvenience allowances for teachers working in the rural environment in order to encourage them to stay so that the pupils in rural areas will not be denied of quality education.

- On gender equality promotion and women liberation, government, private sectors and the NGOs should create more awareness to discourage early marriage among women and encourage women to embrace education.

- Women should be given more slots in the politics of Ghana and public sectors in order to be involved in decision making process. 
- Government should establish mother and child hospital in each local government to provide free delivery and health care for both the mother and child so as to reduce infant death rate and enhance mother's wellbeing.

- Government should encourage seminars, workshops and consistent health education of women by health workers and other stakeholders in health sector to reduce the rate of child and mother's death in Ghana.

- Ghana should seek to produce more health professionals by establishing Nursing schools, Medical Universities, Health schools so as to combat the challenge of inadequate health workers.

- There should be more monitoring of all the grants, foreign aid and government expenditures on HIV/AIDS and malaria in Ghana.

- Government of Ghana through health workers should increase awareness on HIV/AIDS and malaria. Personal hygiene should be taught in schools and public society.

- Intentional spreading of HIV/AIDS should be declared a grievous offence with severe punishment. People should be made to know their HIV/AIDS status.

- There should be policy and implementation on waste management in Ghana. Management of waste should be contracted out to waste management firms and enforced by the law enforcing agents. Also, there should be a monthly national sanitation day preferably on weekends when most public offices will be closed. This should be made compulsory to all the citizens in order to reduce malaria and outbreak of other diseases such as cholera.

- Government should intensify efforts on the provision of water with the assistance of private sectors and NGOs for environmental sustainability.

- Government of Ghana should take more serious the enforcement of policies associated with environmental sustainability such as deforestation, tree planting and pollution. Non-compliant people should be made to face the wrath of law in order to serve as deterrent to other erring citizens. 
- Foreign aid and grants should be judiciously spent in the area of targeted development with proper monitoring for efficiency in order to attract more global support.

- Corruption and misappropriation of funds should be discouraged to the least minimum.

- Democracy should be strengthened most especially in the area of accountability and community participation. Also, ethnic crises or any form of insurgency must be suppressed so as to create a peaceful atmosphere for foreign partnership.

\section{Conclusion}

The commitment of Ghana to achieving the millennium development objectives is very impressive. This is reflected in government policies with remarkable development since 2001 when Ghana started implementing the millennium development goals. The biennial developmental reports since 2002 contain the remarkable improvement in Ghana's standard of living. Ghana therefore has the greater chance of becoming one of the fast growing and developing nations in Africa and the world at large if the challenges undermining the millennium development goals are resolved. The need therefore for Ghana to focus more on solving these problems is strategic for a better result in this new era of Sustainable Development Goals.

\section{List of References}

- Aboderin, I. (2004). Modernization and ageing theory revisited: current explanations of recent developing world and historical western shifts in material family support for older people. Aging and society.

- Eisenstadt, S. N. (1966). Modernization: Protest and Change, Englewood Cliffs, NJ: PrenticeHall.

- Ghana Demographic Health Survey (1993-2008). Ghana Statistical Health Service. Accra: Ghana.

- Ghana Demographic Health Survey (2014). Ghana Statistical Health Service. Accra: Ghana. 
- Ghana Millennium Development Goals (2010). United Nations Development Programme. Accra: Ghana.

- Ghana Millennium Development Goals Report (2015). United Nations Development Programme. Accra: Ghana.

- Ghana Statistical service (1995). Ghana Living Standards Survey: Report of the Third Round (GLSS3). Accra: GSS.

- Ghana Statistical service (1998). Ghana Living Standards Survey: Report of the Fourth Round (GLSS4). Accra: GSS.

- Ghana Statistical service (2008). Ghana Living Standards Survey: Report of the Fifth Round (GLSS5). Accra: GSS.

- Ghana Statistical Service (2014). Ghana Living Standards Survey: Report of the Sixth Round (GLSS 6). Accra: GSS.

- Gilman, N. (2203). Mandarins of the Future: Modernization Theory in Cold War America, Baltimore: The John Hopkins University Press.

- Global Forest Resources Assessment (2010). Food and Agriculture Organization of United Nations.

- $\quad$ Michael J. A., \& John K., 2001. Modernization Theory. Encyclopedia of Sociology, Vol. 3.

- Ministry of education (2014). Education Management Information. Accra: Ministry of Education.

- Ministry of Health (2008a). Centre for Health Information Management. Accra: Ministry of Health.

- Ministry of Health (2008b). Ghana Maternal Health Survey 2007, Accra, Ghana.

- Ministry of Health 2008c). Health Sector Programme of Work 2008 Reviews. Accra: Ghana Health Service.

- Ministry of Health (2009a). HIV Sentinel Survey Report 2008. Accra: Ministry of Health.

- Ministry of Health (2009b). National HIV Prevalence and AIDS Estimates Report, 2007-2012. Accra. Ministry of Health.

- Ministry of Health (2009c). Malaria Control Programme Report 2008. Accra: Ministry of Health. 
- Ministry of Health (2013). Ghana Holistic Assessment of the Health Sector Programme of Work 2012. Accra: Ministry of health.

- National Malaria Control Programme Annual Report (2009). Ghana Health Service. Accra: Ghana.

- Schwartz, B. I. (1972). The limits of 'tradition versus modernity' as categories of explanation: The case of Chinese intellectuals. Daedalus, 101(2).

- World Health Organization (2014). Trends in Maternal Mortality: 1990 to 2013: Estimates by WHO, UNICEF, UNFPA, the World Bank and the United Nations Population Division. Geneva: WHO.

\section{AUTHORS' CONTACT:}

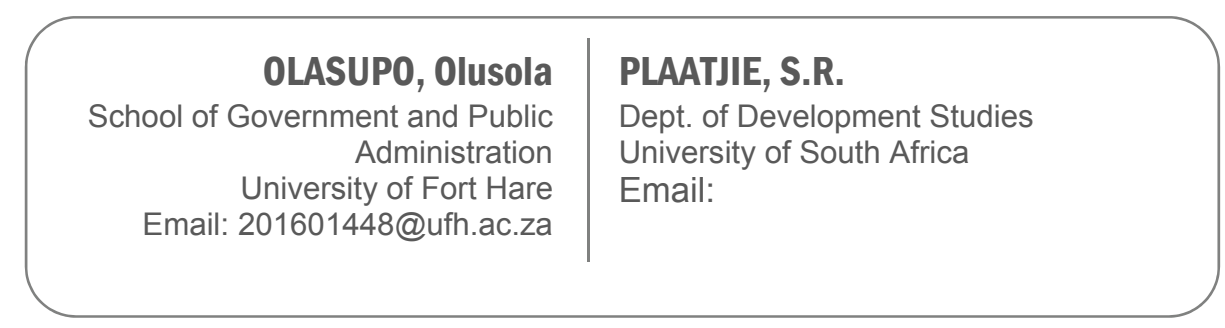

